\title{
Estimation of the environmental attributable fraction of asthma among Canadian children: a systematic review
}

\author{
E Simons ${ }^{*}, T$ To, S Dell
}

From Canadian Society of Allergy and Clinical Immunology Annual Scientific Meeting 2009

Halifax, Canada. 22-25 October 2009

\section{Background}

We systematically summarized studies that evaluated the associations between environmental exposures and asthma development by calculating the population attributable fraction (PAF) of Canadian childhood asthma due to modifiable environmental exposures.

\section{Methods}

Asthma incidence among Canadian children was estimated from population-based surveys and administrative datasets. The prevalence of Canadian exposure to airborne pollutants, environmental tobacco smoke (ETS), indoor allergens, and home mould and moisture were determined from peer-reviewed publications and government reports. International estimates of the relative risk of physician-diagnosed asthma were determined from peer-reviewed studies and used to determine attributable risk (AR) for PAF calculation.

$$
\mathrm{PAF}=\frac{\mathrm{AR} * \text { Exposure prevalence }}{\text { Asthma incidence }} * 100 \%
$$

\section{Results}

The Canadian childhood asthma incidence was between $2.8 \%$ and $5.3 \%$. Canadian exposure prevalences were: $\mathrm{PM}_{10} 16 \%$, outdoor $\mathrm{PM}_{2.5} 7.1 \%$, indoor $\mathrm{PM}_{2.5} 1.7 \%$, outdoor $\mathrm{NO}_{2} 25 \%$, indoor $\mathrm{NO}_{2} 3.3 \%, \mathrm{O}_{3} 22 \%, \mathrm{SO}_{2} 0.1 \%$, CO $0.1 \%$, environmental tobacco smoke (ETS) $9.0 \%$, cat $22 \%$, dog $12 \%$, mouse $17 \%$, cockroach $1.7 \%$, dust mite $30 \%$, moisture $14 \%$, and mould $33 \%$. Median odds ratios of physician-diagnosed asthma used to determine the AR were above 1.00 for $\mathrm{PM}_{10}, \mathrm{PM}_{2.5}, \mathrm{NO}_{2}, \mathrm{CO}$, ETS, mouse, cockroach, moisture, and mould. The PAF estimates were: $\mathrm{PM}_{10} 11 \%$, outdoor $\mathrm{PM}_{2.5} 1.2 \%$, indoor $\mathrm{PM}_{2.5} 0.30 \%$, outdoor $\mathrm{NO}_{2} 1.4 \%$, indoor $\mathrm{NO}_{2} 0.19 \%$, ETS $4.0 \%$, mouse $3.8 \%$, cockroach $0.22 \%$, moisture $4.5 \%$, mould $10 \%$, and 0 for $\mathrm{O}_{3}, \mathrm{SO}_{2}, \mathrm{CO}$, cat, dog, and dust mites.

\section{Conclusions}

This systematic review suggests contributions to Canadian childhood asthma development from exposure to particulates, $\mathrm{NO}_{2}$, ETS, mouse, cockroach, mould, and moisture, although the results are not consistent enough to imply causation. The associations with cat, dog and dust mite allergen exposure appear to be more complex. These findings highlight the need for longitudinal methods to more accurately estimate the contributions of modifiable environmental exposures to childhood asthma development.

Published: 12 May 2010

doi:10.1186/1710-1492-6-S1-P8

Cite this article as: Simons et al:: Estimation of the environmental

attributable fraction of asthma among Canadian children: a systematic review. Allergy, Asthma \& Clinical Immunology 2010 6(Suppl 1):P8.

\footnotetext{
* Correspondence: elinor.simons@sickkids.ca

Child Health Evaluative Sciences, The Hospital for Sick Children Research

Institute, 555 University Avenue, Toronto, ON, Canada M5G 1X8
} 